\title{
AVALIAÇÃO DA ASSISTÊNCIA DE ENFERMAGEM EM UNIDADE NEONATAL NA PERSPECTIVA DOS PAIS
}

Kayna Trombini Schmidt ${ }^{1}$, Fernanda Tessari de $\mathrm{Mello}^{2}$, Edilaine Giovanini Rosseto ${ }^{3}$, Sarah Nancy Deggau Hegeto de Souza ${ }^{3}$

RESUMO: O objetivo deste estudo descritivo foi verificar como os pais percebem a assistência realizada pela equipe de enfermagem das Unidades Neonatais de um hospital de ensino em Londrina. Os critérios de inclusão dos sujeitos foram: ser pai de neonato com tempo de internação superior a 15 dias e com idade gestacional de nascimento menor que 32 semanas ou peso de nascimento inferior a $1500 \mathrm{~g}$. Participaram da pesquisa 35 pais, que responderam ao questionário proposto. Quanto ao suporte de comunicação, eles demonstraram satisfação com as informações recebidas, porém demandaram ser escutados e incluídos nas decisões sobre seu filho. No suporte instrumental, sentiram-se apoiados na apropriação do papel de pais e consideraram bom o cuidado prestado aos bebês. Os resultados deste estudo não podem ser estendidos a toda população atendida, mas indicam a necessidade de aplicação sistemática do instrumento para a avaliação da assistência de enfermagem.

PALAVRAS-CHAVE: Prematuro; Papel do profissional de enfermagem; Pais.

\section{EVALUATION OF NURSING CARE IN NEONATAL UNIT BY THE PARENTS' PERSPECTIVE}

\begin{abstract}
The purpose of this descriptive study was to determine how parents perceive the care performed by nursing staff of the Neonatal Unit of a teaching hospital in Londrina. Inclusion criteria of subjects were: the father of a newborn with length of stay exceeding 15 days and with gestational age less than 32 weeks or birth weight below $1500 \mathrm{~g}$. 35 parents participated in the study and responded to the questionnaire proposed. Regarding the communication support, they expressed satisfaction with the information received, but demanded to be heard and to be included in decisions about their child. Regarding the instrumental support, they felt supported in the appropriation of the role of parents and considered as good the care given to the babies. The results of this study cannot be extended to the entire target population, but indicate the need for systematic application of the instrument for the evaluation of nursing care. KEYWORDS: Premature infant; Role of professional nursing; Parents.
\end{abstract}

\section{EVALUACIÓN DE LA ASISTENCIA DE ENFERMERÍA EN UNIDAD NEONATAL EN LA PERSPECTIVA DE LOS PADRES}

RESUMEN: El objetivo de este estudio descriptivo fue verificar cómo los padres perciben la asistencia realizada por el equipo de enfermería de las Unidades Neonatales de un hospital de enseñanza en Londrina. Los criterios de inclusión de los sujetos fueron: ser padre de neonato con tiempo de internación superior a 15 días y con edad de gestación de nacimiento menor que 32 semanas o peso de nacimiento inferior a $1500 \mathrm{~g}$. Han participado de la investigación 35 padres, que contestaron al cuestionário propuesto. Cuanto a la comunicación, ellos manifestaron satisfacción con las informaciones recibidas, pero demandaron ser escuchados y incluidos en las decisiones sobre su hijo. En suporte instrumental, se sintieron apoyados en la apropiación del papel de padres y consideraron bueno el cuidado prestado a los bebés. Los resultados de este estudio no pueden ser extendidos a toda la población atendida, pero apuntan la necesidad de aplicación sistemática del instrumento para la evaluación de la asistencia de enfermería.

PALABRAS CLAVE: Prematuro; Papel del profesional de enfermería; Padres.

${ }^{1}$ Enfermeira Neonatologista. Mestranda em Enfermagem na Universidade Estadual de Maringá-UEM.

${ }^{2}$ Enfermeira Residente em Saúde da Criança na Universidade Estadual de Londrina-UEL.

${ }^{3}$ Enfermeira. Mestre em Enfermagem Fundamental. Docente do Departamento de Enfermagem da UEL.

Autor correspondente:

Kayna Trombini Schmidt

Universidade Estadual de Maringá

Rua Cambuquira, 213 - 86062-440 - Londrina-PR, Brasil Recebido: 22/02/10

E-mail: kayna411@yahoo.com.br

Aprovado: 15/06/10

Cogitare Enferm. 2010 Jul/Set; 15(3):460-6 


\section{INTRODUÇÃO}

O nascimento prematuro é sempre uma situação de grande estresse e crise para a família. Quando isso acontece, a estrutura elaborada pelos pais para o bebê se abala, muitas vezes dando lugar à insegurança, medo e expectativa. Um filho nascido prematuramente ou com alguma patologia geralmente leva os pais a se sentirem angustiados e impotentes ${ }^{(1)}$.

$\mathrm{O}$ ambiente das Unidades Neonatais apresenta várias fontes geradoras de estresse tanto para a equipe de saúde como para os pais. A adaptação ao novo contexto causador de estresse é um processo particular, de maneira que cada pessoa tem diferentes níveis de capacidade de enfrentamento ${ }^{(2)}$. Os pais também podem apresentar pesadelos constantes relacionados à situação de estresse vivenciada, e alterações comportamentais como resistência em cuidar da criança ou segurá-la e dificuldade em ajudar nos cuidados. Em estudo realizado com pais de prematuros, se encontrou que $28 \%$ dos pais entrevistados desenvolveram sintomas de estresse pós-traumático (EPT) $)^{(3)}$. O estresse vivenciado pela família, principalmente nas primeiras semanas de internação, são precursores do distúrbio de EPT, o que pode influenciar no envolvimento dos pais com seus filhos, especialmente no estabelecimento de vínculo.

Nas Unidades Neonatais, os laços afetivos entre pais e filhos quase sempre são comprometidos em razão das rotinas impostas pela instituição e condições clínicas do próprio prematuro. O longo período de internação também está relacionado ao maior risco dos pais de desenvolver distúrbios psicológicos como depressão e baixa autoestima ${ }^{(4)}$.

Ao gerar um filho prematuro, as progenitoras enfrentam uma nova realidade, causando sentimentos paradoxos, muitas vezes incompreendidos pelos profissionais da saúde. É preciso compreender que, nesse processo, a mãe também é prematura, devendo ser cuidada de forma individualizada e diferenciada ${ }^{(4)}$.

As intervenções de suporte aos pais devem ser realizadas por meio de fornecimento de informações realistas, coerentes e ditas de maneira que os pais consigam compreender o real estado de saúde de seu filho e sintam-se personagens ativos no estabelecimento do tratamento e aprendizagem dos cuidados específicos que seu bebê possa necessitar após a altat ${ }^{(3)}$. Portanto, a equipe de enfermagem assume um leque de atribuições, capacidades e responsabilidades que são essenciais para avaliar, compreender e apoiar com segurança o RN e a sua família durante esse tempo crítico $^{(5)}$.

Nas Unidades Neonatais de um hospital de ensino em Londrina é desenvolvido um projeto cuja finalidade é criar uma rede de apoio às famílias de bebês nascidos prematuramente. O projeto conta com uma equipe multiprofissional composta por residentes de Enfermagem e Medicina, alunos de graduação em Enfermagem, assistente social, psicóloga, fonoaudióloga e docentes de Enfermagem e Medicina que prestam atendimento integrado ao $\mathrm{RN}$ de risco e sua família, com levantamento de problemas e estabelecimento de metas a serem alcançadas.

A equipe propõe o atendimento individualizado e humanizado, oferecendo suporte a essas famílias no enfrentamento das situações advindas da demanda de cuidado do seu filho prematuro ${ }^{(6)}$. Para isso, acompanha e orienta a primeira visita dos pais o mais precoce possível na Unidade Neonatal, propicia atendimento individualizado semanal com a família, estimula a posição Canguru, incentiva o aleitamento materno, esclarece dúvidas e realiza o preparo da família para a alta hospitalar. O projeto tem como base o cuidado centrado na família, que é uma filosofia que envolve a parceria entre os profissionais e a família, com o objetivo de estimular a presença dos pais na Unidade Neonatal, sua participação no cuidado infantil e a comunicação com os profissionais ${ }^{(7)}$.

Além destes cuidados prestados no período de internação e após a alta hospitalar, as enfermeiras residentes fazem acompanhamento ambulatorial destes bebês até um ano de idade, considerando-se ser este um período importante para a adaptação da família ao cuidado com a criança. Diante de tal proposta de assistência, este trabalho teve o objetivo de verificar como os pais percebem a assistência de enfermagem realizada pela equipe de enfermagem durante o período de internação de seus filhos prematuros nas Unidades Neonatais.

\section{METODOLOGIA}

Trata-se de um estudo quantitativo-descritivo, realizado em um hospital de ensino, sendo este um hospital público de nível terciário. O hospital em que foi realizada a pesquisa é referência na região para gestação de risco e possui uma Unidade de Terapia Intensiva Neonatal (UTIN) com sete leitos e uma Unidade de Cuidados Intermediários Neonatal (UCIN) com 10 leitos, ambas com taxa média de ocupação 
acima de sua capacidade.

Como critério de inclusão na pesquisa, foi estabelecido o período mínimo de 15 dias de internação, considerando-se a necessidade de um tempo de convivência de pais com a equipe para responder ao questionário; peso de nascimento menor que $1500 \mathrm{~g}$ ou idade gestacional menor que 32 semanas. A população de estudo foi composta por 35 pais de bebês que ficaram internados nas Unidades Neonatais do hospital de ensino em Londrina e foram acompanhados pelo projeto "Uma rede de apoio à família prematura"(()). Os dados foram coletados entre maio e outubro de 2009 . O questionário foi aplicado aos pais nas Unidades Neonatais e, no caso dos bebês que já tinham recebido alta hospitalar, a abordagem foi realizada em visita domiciliar ou no Ambulatório do Hospital de Clínicas, onde são realizadas as consultas de seguimento ambulatorial.

O instrumento utilizado para coleta de dados foi o questionário Nurse Parent Support Tool (NPST) ${ }^{(8)}$, adaptado transculturalmente e validado para a língua portuguesa ${ }^{(9)}$, sendo denominado questionário "Suporte de Enfermagem oferecido aos Pais". O NPST foi criado para avaliar o apoio que os profissionais oferecem às famílias no momento da internação de seus filhos, objetivando proporcionar uma relação mais solidária com os pais nessa situação ${ }^{(8)}$. Constitui-se um instrumento semiestruturado com 21 questões fechadas cujas alternativas seguem a seguinte pontuação: 1- nunca; 2- raramente; 3- às vezes; 4 - na maioria das vezes e 5-sempre.

O questionário foi proposto em quatro subdimensões: suporte de comunicação e informações fornecidas à família (nove questões); suporte emocional (três questões); suporte de incentivo (quatro questões); suporte instrumental (cinco questões) ${ }^{(8,10)}$. O suporte de comunicação e informações fornecidas à família abrange o tratamento, desenvolvimento e cuidados, assim como ensinamentos à família sobre os comportamentos, respostas e necessidades da criança, e manter a família ciente de seus direitos e responsabilidades durante a hospitalização de seu filho. O suporte emocional envolve o comportamento de escuta da equipe, demonstração de afeto, consideração e relação de confiança. O suporte de incentivo reporta-se à afirmação e feedback das informações e reforço aos pais ao exercer seu papel com a criança. $\mathrm{O}$ suporte instrumental se refere a prestar bom cuidado ao recém-nascido e oferecer todo tipo de apoio que os pais precisarem abrangendo qualidade no cuidado físico e psicossocial ${ }^{(8)}$.
Após esclarecimentos sobre a pesquisa e garantia do sigilo dos dados coletados apenas para com finalidade científica, o Termo de Consentimento Livre e Esclarecido foi assinado pelos pais antes de responderem aos questionários. O pesquisador permaneceu próximo aos sujeitos para esclarecer qualquer dúvida enquanto estes respondiam o questionário. Os dados socioeconômicos foram coletados na ficha de acompanhamento das famílias do projeto ${ }^{(6)}$. Para análise dos dados utilizou-se o programa Epi Info 3.3.2, obtendo-se as médias a partir da escala de Likert e apresentadas nos resultados deste trabalho. Este estudo foi aprovado pelo Comitê de Ética e Pesquisa do HURNP, conforme parecer n. 250/08.

\section{RESULTADOS E DISCUSSÃO}

Dos 35 entrevistados, $97 \%$ eram do sexo feminino com faixa etária predominante entre 20 e 34 anos (77\%) e tendo o ensino médio incompleto (35\%) e completo (35\%) como níveis de escolaridade mais frequentes, representando $70 \%$ da população entrevistada. A população apresentou bom nível de entendimento do instrumento e discernimento nas respostas às questões

Tabela 1 - Características sociodemográficas de pais dos prematuros internados em um Hospital de ensino. Londrina, 2009.

\begin{tabular}{lcc}
\hline Características & n. & \% \\
\hline Idade & 6 & 17 \\
$<20$ anos & 27 & 77 \\
20 a 34 anos & 2 & 6 \\
$>35$ anos & & \\
Estado Civil & 7 & 20 \\
Sem companheiro & 28 & 80 \\
Com companheiro & & \\
Escolaridade & 9 & 25 \\
Fundamental & 12 & 35 \\
Médio Incompleto & 12 & 35 \\
Médio Completo & 2 & 5 \\
Superior & & \\
Trabalho Remunerado & 25 & 72 \\
Sim & 10 & 28 \\
Não &
\end{tabular}

aplicadas. Quanto ao estado civil, $80 \%$ da população estudada tinham companheiro estável e $72 \%$ exerciam trabalho remunerado (Tabela 1).

Em relação à frequência habitual de visita ao RN durante o período de internação, $72 \%$ dos pais 
referiram fazer visitas diárias ao bebê, $23 \%$ visitavam em três a seis dias por semana e $5 \%$ visitavam em menos que três dias por semana. Essa alta frequência de visitas pode refletir um indicador de bom vínculo entre os pais e o bebê. O estímulo da equipe para a realização das visitas e o bom vínculo dos profissionais com os pais propicia a presença destes dentro das Unidades Neonatais.

$\mathrm{Na}$ análise do perfil dos prematuros internados, $54 \%$ eram do sexo feminino. Ao nascer, $70 \%$ dos prematuros tinham peso de nascimento maior que $1000 \mathrm{~g}$ e, quanto à idade gestacional de nascimento, $80 \%$ tinham entre 26 e 31 semanas. Com referência ao tempo de internação desses bebês, $68 \%$ ficaram de 30 a 60 dias, sendo um período suficiente para avaliar e participar das rotinas nas Unidades de Cuidados Neonatal. A média do tempo de internação foi de 52 dias (Tabela 2).

Ao analisar a pontuação obtida nas respostas dos pais às questões do instrumento, foi possível perceber que, na maioria das questões, o resultado foi satisfatório, com médias acima de quatro ("maioria das vezes"), o que pode indicar que seja uma prática incorporada pela equipe. Porém, algumas questões mostraram médias abaixo de três ("raramente") (Tabela 3).

Tabela 2 - Características demográficas dos recém-nascidos internados nas Unidades de Cuidados Neonatais em um hospital de ensino. Londrina, 2009.

\begin{tabular}{lll}
\hline Características & n. & \% \\
\hline Sexo & 19 & 54 \\
Feminino & 16 & 46 \\
Masculino & & \\
Idade Gestacional & 28 & 80 \\
26 - 31 semanas & 7 & 20 \\
32 - 36 semanas & & \\
Peso ao nascer & 7 & 30 \\
$<1000$ g & 28 & 70 \\
$\geq 1000$ & & \\
Tempo de Internação & 4 & 11 \\
$<30$ dias & 24 & 68 \\
30 a 60 dias & 7 & 21 \\
$>60$ dias &
\end{tabular}

Tabela 3 - Médias de pontuação obtidas do questionário "Suporte de Enfermagem oferecido aos Pais", aplicado em um hospital escola nas Unidades Neonatais. Londrina, 2009.

\begin{tabular}{lc}
\hline Subdimensões & Média (Escala de Likert) \\
\hline Suporte de Comunicação e Informações fornecidas à família & \\
Ajudou-me a falar sobre meus sentimentos, angústias e preocupações & 3,8 \\
Ajudou-me a entender o que estava sendo feito com meu filho(a) & 4,3 \\
Deixou-me decidir se queria ficar ou sair durante os procedimentos técnicos & 2,7 \\
Respondeu satisfatoriamente às minhas perguntas ou indicou alguém que pudesse respondê-las & 4,5 \\
Informou-me sobre mudanças ou melhoras do estado do meu filho(a) & 4,8 \\
Incluiu-me em discussões para tomar decisões sobre o cuidado do meu filho(a) & 2,3 \\
Ajudou-me a entender o comportamento e as reações do meu filho(a) & 4,0 \\
Deu atenção às minhas preocupações ou angústias & 4,1 \\
Ajudou-me a conhecer os nomes e funções dos membros da equipe que cuidava de meu filho & 4,0 \\
Suporte emocional & \\
Demonstrou preocupação em relação ao meu bem-estar & 3,5 \\
Demonstrou gostar do meu filho(a) & 4,7 \\
Foi otimista em relação ao meu filho(a) & 4,6 \\
Suporte de incentivo & 4,8 \\
Fez-me sentir importante como pai/mãe & 4,3 \\
Permitiu-me saber que eu estava fazendo algo de bom ao ajudar meu filho(a) & 4,7 \\
Encorajou-me a fazer perguntas sobre meu filho(a) & 4,5 \\
Permitiu meu envolvimento no cuidado do meu filho(a) sempre que possível & \\
Suporte instrumental & 4,7 \\
Ensinou-me como cuidar do meu filho(a) & 3,8 \\
Orientou-me como confortar meu filho(a) durante ou após os procedimentos & 5,0 \\
Prestou um bom cuidado ao meu filho(a) & 4,6 \\
Foi sensível às necessidades especiais do meu filho(a) & 4,5 \\
Atendeu às necessidades do meu filho(a) na hora certa & \\
\hline
\end{tabular}


Embora seja inegável a importância da inclusão da família no cuidado ao bebê e participação na tomada de decisões sobre seu filho, as condutas são ditadas primeiramente por normas administrativas estabelecidas pela instituição e pela equipe, visando o bom andamento das atividades. As intervenções de suporte à família nas Unidades Neonatais não são integradas às rotinas dos serviços ${ }^{(11)}$.

Na subdimensão suporte de comunicação e informações fornecidas à família, as questões "Deixou-me decidir se queria ficar ou sair durante os procedimentos técnicos" e "Incluiu-me em discussões para tomar decisões sobre o cuidado do meu filho (a)." obtiveram médias de 2,7 e 2,3 respectivamente, sendo as menores médias encontradas na pesquisa. Podem-se observar mudanças, ainda que discretas e gradativas, nas Unidades Neonatais em relação à inserção da família nas decisões e assistência ao prematuro. Observa-se uma tendência crescente de incorporação, por parte da equipe, dos princípios do cuidado centrado na família, que são: dignidade e respeito, colaboração da família, informação partilhada e participação dos pais no cuidado $^{(7)}$. Porém, o presente estudo demonstra que, no que tange à subdimensão de comunicação, precisa haver maior disponibilidade da equipe para que os pais se sintam envolvidos e respeitados em suas vontades e necessidades.

Por muito tempo as decisões referentes ao tratamento e cuidados técnicos ao recém-nascido hospitalizado restringiram-se à equipe de saúde, e mesmo após várias mudanças recomendadas nas rotinas das UTI neonatais, ainda encontramos barreiras para a implementação de práticas diferenciadas. Mesmo em questões simples como a entrada dos pais na unidade, há divergências nas instituições, e estes ficam sujeitos às restrições de horário para visita ${ }^{(12)}$.

Em relação à permanência dos pais em tempo integral na Unidade Neonatal, pode-se destacar, também, limitações relacionadas, principalmente, à estrutura física que não é adequada para a acomodação das famílias. Esta dificuldade não se restringe apenas à instituição onde este estudo foi realizado, mas também diz respeito a outras instituições. Alguns autores colocam, ainda, outras justificativas utilizadas para restringir a permanência da mãe na unidade, tal como escassez de recursos humanos, horário da visita médica e execução de procedimentos invasivos ${ }^{(12)}$. A permanência da família durante procedimentos técnicos pode ser viabilizada com o auxílio da equipe de enfermagem. Os pais devem estar esclarecidos sobre o procedimento técnico antes de ser realizado e, caso concordem em permanecer junto ao seu filho durante a execução do mesmo, devem ser respeitados e orientados sobre como ajudar durante o procedimento.

No suporte instrumental, a questão "Orientoume como confortar meu filho(a) durante ou após os procedimentos" apresentou média de 3,8, e reforça questões anteriores sobre participação da família. Acredita-se que a população estudada sente a necessidade de atuar no cuidado dos seus filhos. É comum solicitar aos pais que se retirem durante admissão de outros bebês e procedimentos diversos executados na unidade, sendo que o tempo gasto nessas ocasiões pode, muitas vezes, exceder o tempo que os pais conseguem permanecer no hospital para estar com seu bebê( ${ }^{(7)}$.

Os pais demandam orientação a respeito das preferências de seu filho, ressaltando as necessidades particulares de cada bebê, pois apenas informações sobre as condições clínicas do bebê não se mostram suficientes. No cuidado com o bebê, os pais devem conhecer as medidas não-farmacológicas, de acolhimento e conforto que eles podem fazer para interagir com seu filho e ajudá-lo durante os procedimentos ${ }^{(7)}$. Medidas como essas podem melhorar o vínculo entre pais e filho, além de fortalecer a confiança dos pais em sua participação durante o processo de hospitalização do bebê e no cuidado ao recém-nascido, após a alta hospitalar.

Em contrapartida, a média máxima $(5,0)$ obtida na questão "Prestou um bom cuidado ao meu filho(a)" mostra que os pais têm confiança no cuidado prestado pela equipe de enfermagem. Durante a realização deste estudo, os entrevistados ressaltaram a satisfação em relação ao cuidado com o bebê, sendo este um importante indicador apontado pelo questionário "Suporte de Enfermagem oferecido aos Pais".

Em comparação com estudo realizado em Hong Kong ${ }^{(10)}$, utilizando o NPST, mesmo com as diferenças culturais, obtivemos resultados semelhantes e o suporte de comunicação e informações fornecidas à família destacou-se como mais relevante para os pais. Foi encontrada média similar na questão "Informou-me sobre mudanças ou melhoras no estado do meu filho(a)" e, no presente estudo, obtivemos média superior na questão "Respondeu satisfatoriamente às minhas perguntas ou indicou alguém que pudesse respondê-las", com 4,5 pontos. Vale ressaltar que os entrevistados reforçaram a atuação das enfermeiras residentes como responsáveis por fornecer muitas informações. Acreditamos que isso se justifique pelo contato constante das residentes na assistência aos bebês e pelo trabalho 
desempenhado junto às famílias, que possibilita maior vínculo com as mesmas, tornando as enfermeiras residentes uma referência para os pais.

Para que a família receba atenção de maneira integral, é necessário envolvimento, principalmente da equipe de enfermagem, já que esta permanece constantemente no cuidado direto ao $\mathrm{RN}$ e à família. A percepção verbalizada pelos pais sobre as enfermeiras como principais responsáveis por fornecer informações a respeito de seu bebê justifica-se pela maior acessibilidade destes membros da equipe de saúde à família. Desta maneira, como a equipe de enfermagem permanece realizando os cuidados ao $\mathrm{RN}$ continuamente, encontra-se em uma posição chave para dar informações que possam servir de apoio aos pais ${ }^{(7)}$. Outro estudo afirma, ainda, que as enfermeiras são responsáveis por traduzir as terminologias médicas aos pais, de maneira que compreendam as informações ${ }^{(10)}$.

Na subdimensão suporte emocional, a questão que obteve menor média foi "Demonstrou preocupação em relação ao meu bem-estar." Esse resultado aponta a necessidade da população entrevistada em sentir-se também cuidada pela equipe. Todo estresse causado pela internação do recém-nascido prematuro produz alguns efeitos na família, e, dentro das Unidades Neonatais, a ênfase é dada ao bebê e aos procedimentos para sua melhora física. Apesar de reconhecer o recebimento de orientações na maioria das vezes, aparece outra demanda de cuidado: a família tem necessidade de sentir-se também cuidada e de ser escutada. O hospital de ensino conta com o auxílio da Psicologia que faz atendimento aos pais, porém a equipe de enfermagem também deve estar atenta às necessidades de cada família. A escuta por parte da equipe de enfermagem é um instrumento de apoio aos pais, representando a força necessária para o enfrentamento da hospitalização do seu filho ${ }^{(10)}$.

$\mathrm{Na}$ subdimensão suporte de incentivo, este estudo encontrou nas quatro questões correspondentes médias superiores a 4,3, sendo a maior média 4,8 na questão "Fez-me sentir importante como pai/mãe". Na comparação com outro estudo, que também aplicou o mesmo instrumento, as médias encontradas nessa subdimensão foram inferiores ao presente estudo. Supõe-se que essa pontuação elevada possa ser justificada pela atenção sistemática ao introduzir as mães nos pequenos cuidados, ainda na Unidade Neonatal. A atuação das enfermeiras residentes junto à equipe de enfermagem proporciona maior possibilidade de ações educativas com os pais, suporte de informação e estímulo à inserção da família nos cuidados, assim como a realização da posição canguru, mesmo em bebês em ventilação pulmonar mecânica (VPM) quando em condições clínicas favoráveis.

A prática da posição canguru com bebês ainda em uso de VPM também é uma valiosa estratégia utilizada junto ao bebê prematuro e sua família. A posição canguru colabora em diversos aspectos como: auxilio à manutenção da produção láctea e estímulo à mãe, melhora do vínculo entre mãe e bebê, apropriação da mãe em relação a seu filho quando o toma em seus braços e o tem junto de si, o que traz perceptível bem estar do bebê durante o posicionamento em canguru devido à melhor organização. Outra vantagem desta prática é a enorme satisfação verbalizada pelos pais, gerando boas expectativas quanto à próxima visita, para poder desfrutar novamente dessa vivência.

A vivência nas Unidades Neonatais evidencia que a inserção dos pais na assistência ao bebê e acessibilidade às informações de acordo com a demanda da família, nas diferentes fases de internação, torna os pais mais confiantes no cuidado com seu filho. Ao cuidar de seus filhos, as mães podem direcionar seus esforços para medidas com as quais elas se sintam atuantes no tratamento do bebê, aliviando também suas ansiedades.

$\mathrm{Na}$ formação acadêmica dos profissionais de saúde, o aprendizado é focado no exercício do cuidado físico e orientações aos clientes, sem ênfase na prática da escuta terapêutica. Reforçamos que manter a família informada sobre as mudanças no quadro clínico é tão importante quanto a busca do restabelecimento clínico do paciente. Assim, também é necessário perceber outras demandas na assistência ao bebê e sua família, por meio da escuta terapêutica, de maneira a visualizar integralmente o paciente durante a internação e as condições requeridas para a alta do mesmo.

A pesquisa em questão traz como benefício a possibilidade de ser realizada por meio de um questionário multidimensional, traduzido e validado para avaliação da assistência ao recém-nascido nas Unidades Neonatais e apoio à família prematura, na percepção dos pais. Por meio desse instrumento padronizado, a avaliação pode ser replicada em outros contextos e permite comparação com outras realidades.

\section{CONCLUSÃo}

Este estudo oportunizou identificar as percepções de um grupo de pais sobre a assistência 
de enfermagem ao $\mathrm{RN}$ prematuro por meio de um questionário padronizado. Os resultados apontaram a satisfação com a qualidade da assistência oferecida e o desejo dos pais pela inclusão nas decisões e nos cuidados realizados com seus filhos durante o processo de internação. A aplicação deste instrumento mostrou lacunas do processo assistencial e apontou para uma reflexão sobre as rotinas no ambiente de trabalho da Enfermagem, visto que todas as ações devem ser voltadas para favorecer a recuperação do prematuro e o preparo da família para seu cuidado após alta hospitalar.

Os entrevistados referiram grande satisfação em relação às informações fornecidas pela equipe de enfermagem, em especial as enfermeiras, reforçando a importância do seu papel dentro das Unidades Neonatais no auxílio aos pais sobre o aprendizado dos cuidados especiais demandados pelo prematuro e na superação deste momento crítico. No suporte instrumental, os entrevistados também demonstraram satisfação em relação à equipe de enfermagem, sentindo-se apoiados na melhor apropriação do papel de pais. Cabe ressaltar que os resultados deste estudo representam apenas o grupo entrevistado e não toda população atendida em Unidades Neonatais. Sugere-se a implantação de avaliação sistemática da assistência prestada ao bebê e à família prematura por meio de questionário padronizado, cuja abrangência destaca a individualidade e a importância de cada família e seu bebê.

\section{REFERÊNCIAS}

1. Kamada I, Rocha SMM. As expectativas de pais e profissionais de enfermagem em relação ao trabalho da enfermeira em UTIN. Rev Esc Enferm. USP. [Internet] 2006;40(3) [acesso em 28 jan 2010]. Disponível: http:// tiny.cc/2ewqb

2. Santini AM, Costenaro RGS, Medeiros HMF, Zaberlan C. Estresse: vivência profissional de enfermeiras que atuam em UTI neonatal. Cogitare Enferm. [Internet] 2005;10(3). [acesso em 24 fev 2010]. Disponível: http:// tiny.cc/5yz6c

3. Shaw RJ, Deblois T, Ikuta L, Ginzuburg K, Fleisher B, Koopman C. Acute stress disorder among parents of infants in the neonatal intensive care nursery. Psychosomatics. [Internet] 2006;47(3). [acesso em 28 jan 2010]. Disponível: http://tiny.cc/zqxz1

4. Sales CA, Alves NB, Vrecchi MR, Fernandes J.
Concepções das mães sobre os filhos prematuros em UTI. Rev Bras Enferm. [Internet] 2006;59(1) [acesso em 28 jan 2010]. Disponível: http://tiny.cc/jlze4

5. Moreira MEA. Estressores em mães de recémnascidos de alto risco: sistematização da assistência de enfermagem. [tese]. João Pessoa (PB): Universidade Federal da Paraíba: 2001. In: Reichert APS, Lins RNP, Collet N. Humanização do cuidado da UTI neonatal. Rev Eletron Enfem. [Internet] 2007;9(1) [acesso em 28 jan 2010]. Disponível: http://tiny.cc/la4h2

6. Hayakawa LM, Schmidt KT, Rossetto EG, Souza SNDH, Bengozi TM. Incidência de reinternação de prematuros com muito baixo peso nascidos em um hospital universitário. Esc Anna Nery. No prelo 2010.

7. Griffin T. Family-centered Care in the NICU. J Perinat Neonatal Nurs. 2006; 20(1):98-102.

8. Miles MS, Carlson J, Brunssen, S. The nurse parent support tool manual. [Internet] J Pediatr Nurs 1999 [acesso em 20 abr 2008]. Disponível: http://tiny.cc/ hzkzo

9. Martins TB, Rossetto EG. Adaptação transcultural e validação do instrumento Nurse Parent Support Tool para a língua portuguesa. [monografia] Londrina (PR): Universidade Estadual de Londrina; 2007.

10. Mok E, Leung SF. Nurses as providers of support for mothers of premature infants. J Clin Nurs 2006; 15(6): 726-34.

11. McGrath JM. Family-centered developmental care begins before birth. J Perinat Neonatal Nurs. 2006; 20(3):195-6.

12. Gaíva MAM, Schochi CGS. A participação da família no cuidado ao prematuro em UTI neonatal. Rev Bras Enferm. [Internet] 2005;58(4) [acesso em 28 jan 2010]. Disponível: http://tiny.cc/llxsa 